\title{
Multiplex SYBR Green Real-Time PCR Assay for Detection of Respiratory Viruses
}

\author{
Mozhdeh Sultani ${ }^{1}$; Talat Mokhtari Azad ${ }^{1}$; Mohammadreza Eshragian ${ }^{1}$; Azadeh Shadab ${ }^{1}$; \\ Maryam Naseri ${ }^{1}$; Owrang Eilami ${ }^{2}$; jila Yavarian ${ }^{1, *}$ \\ ${ }_{1}^{1}$ Virology Department, School of Public Health, Tehran University of Medical Sciences, Tehran, IR Iran \\ 2 Department of Infectious Disease, Yasuj University of Medical Sciences, Yasuj, IR Iran \\ ${ }^{*}$ Corresponding author: Jila Yavarian, Virology Department, Tehran University of Medical Sciences, Tehran, IR Iran. Tel: +98-2188962343, Fax: +98-2188962343, \\ E-mail: yavarian@tums.ac.ir
}

Received: March 18, 2014; Revised: June 30, 2014; Accepted: July 25, 2014

\begin{abstract}
Background: It is often difficult for a physician to distinguish between viral and bacterial causes of respiratory infections and this may result in overuse of antibiotics. In many cases of community-acquired respiratory infections, clinicians treat patients empirically. The development of molecular methods for direct detection of viruses has been progressed recently.

Objectives:The objective of this study was recognizing the panel of respiratory RNAviruses by multiplex SYBR Green real-time polymerase chain reaction (PCR).

Materials and Methods: Randomized 172 influenza-negative respiratory specimens of all age groups of hospitalized patients were collected. After RNA extraction, cDNA was synthesized. Three SYBR Green multiplex real-time PCR assays were developed for simultaneous detection of 12 respiratory RNA viruses. Each set of multiplex methods detected four viruses, the first set: respiratory syncytial virus, human metapneumovirus, rhinovirus, enterovirus; the second set: parainfluenza viruses 1- 4 (PIV1-4); the third set: coronaviruses NL63, 229E, severe acute respiratory syndrome (SARS), and OC43.

Results: Application of the multiplex SYBR Green real-time PCR in clinical samples from 172 patients in a one-year study resulted in detection of 19 (11.04\%) PIV3, 9 (5.23\%) PIV4, and 1(0.58\%) coronavirus NL63. All the positive samples were detected during December to March (2011-2012).
\end{abstract}

Conclusions: Multiplex SYBR Green real-time PCR is a rapid and relatively inexpensive method for detection of respiratory viruses.

Keywords: SYBR Green; Real-Time PCR; Respiratory Syncytial Viruses

\section{Background}

Acute respiratory infections (ARIs) are one of the important causes of morbidity and mortality worldwide. World Health Organization has estimated that annually, ARIs are responsible for the death of four million people worldwide (1). The highest percentage of these deaths happens in children in developing countries (2). Symptoms of upper respiratory infections (URI) most commonly include rhinorrhea, sore throat, nasal congestion, sneezing, cough, headache, fever, and in some cases malaise and myalgia; in lower respiratory infections (LRI), the symptoms are pneumonia, bronchitis and bronchiolitis. These symptoms have been seen either in viral or bacterial infections, so it has become a challenge for physicians to differentiate viral causes from bacterial ones, which may decrease the excessive uses of antibiotics (3-5).

Distinguishing the etiology also allows the physician to tell the patients about the assessment and the way of prevention of transmission to others (4). Investigations on respiratory infections have been started since 1933 with isolation of influenza viruses and after three decades other various respiratory viruses have been discovered, but some have remained undetermined because of the low sensitivity of methods (6). Usually, traditional viral culture, generally in combination with serology and direct immunofluorescent (DIF) is the key method for laboratory diagnosis of viral respiratory infections; however, these methods have lower sensitivity, need specific technical expertise and advanced labor instruments, are expensive and are not useful for on-time diagnosis (7).

In some particular situations, the emergence of respiratory viruses has an important impact on health systems worldwide, as happened with the emergence of severe acute respiratory syndrome (SARS)-coronavirus in 2003 which needed emergency diagnosis (8). The development of molecular methods for direct detection of viruses has recently been progressed (9). Polymerase chain reaction (PCR) has become an accepted tool in research since 1984 by Kary Mullis et al. (10) and is being introduced into

Copyright (C) 2015, Ahvaz Jundishapur University of Medical Sciences. This is an open-access article distributed under the terms of the Creative Commons Attribution-NonCommercial 4.0 International License (http://creativecommons.org/licenses/by-nc/4.0/) which permits copy and redistribute the material just in noncommercial usages, provided the original work is properly cited. 
laboratories (11). Singleplex PCR assays amplify one target in different reactions; they are resource intensive and expensive. Multiplex PCR uses a mixture of several distinctive primer pairs in one amplification reaction at the same time (12). Nowadays, various multiplex reverse transcription assays have been developed (13), but until now, there has not been enough study on SYBR Green multiplex real-time PCR for detection of respiratory viruses, a technique shown to be fast and cost effective.

\section{Objectives}

The aim of this study was recognizing the panel of respiratory RNA viruses in hospitalized patients of all age groups during different seasons in one year by SYBR Green multiplex real-time PCR assay.

\section{Materials and Methods}

\subsection{Study Participants}

Randomized 172 respiratory specimens of hospitalized patients with influenza-like illnesses (ILI) of all age groups, negative for influenza viruses, were collected from 23 September 2012 until 22 September 2013 from Na- tional Influenza Center, School of Public Health, Tehran University of Medical Sciences.

\subsection{Laboratory Procedures}

RNA was extracted from $200 \mu \mathrm{L}$ of each sample using high pure viral nucleic acid kit (Roche, Germany). For synthesis of cDNA, $16 \mu \mathrm{L}$ master mix (Fermentas, Germany) consisted of RT-PCR buffer, dNTPs, random hexamer, reverse transcriptase enzyme and RNase inhibitor was mixed with $24 \mu \mathrm{L}$ of extracted RNA. Reverse transcription was performed at $37^{\circ} \mathrm{C}$ for one hour. Three multiplex SYBR Green real-time PCR assays were developed for simultaneous detection of 12 respiratory RNA viruses. Each multiplex set was designed for detection of four viruses as follows: the first set was respiratory syncytial virus (RSV), human metapneumovirus (HMPV), rhinovirus (RV), and enterovirus (EV); the second set was parainfluenza viruses 1-4 (PIV1-4) and the third set was coronaviruses NL63, 229E, SARS, OC43. The next step was primer designing and the most important factor was the Tm of PCR products which must be different in each primer pair for specific detection of each virus according to the melt curve. Table 1 shows the properties of the primers.

\begin{tabular}{|c|c|c|c|c|}
\hline Primer Name & Primer Sequence (5'-3') & Target Gene & Product Length & Product Tm \\
\hline OC43-F & CGATGAGGCTATTCCGACTAGGT & S & 76 & 89.26 \\
\hline OC43-R & CCTTCCTGAGCCTTCAATATAGTAACC & & & \\
\hline SARS-F & AAGCCTCGCCCAAAAACGTAC & $\mathrm{NC}$ & 229 & 99.12 \\
\hline SARS-R & AAGTCAGCCATGTTCCCGAA & & & \\
\hline NL63-F & ACGTACTTCTATTATGAAGCATGATATTAA & $1 a$ & 103 & 81.29 \\
\hline NL63-R & AGCAGATCTAATGTTATACTTAAAACTACG & & & \\
\hline 229E-F & САТАСТАТСААСССАТТСАAСAAG & M & 137 & 94.47 \\
\hline 229E-R & CACGGCAACTGTCATGTATT & & & \\
\hline PIV1-F & ACCTACAAGGCAACAACATC & $\mathrm{HN}$ & 129 & 87.75 \\
\hline PIV1-R & CTTCCTGCTGGTGTGTTAAT & & & \\
\hline PIV2-F & CCATTTACCTAAGTGATGGAA & $\mathrm{HN}$ & 116 & 89.04 \\
\hline PIV2-R & CGTGGCATAATCTTCTTTTT & & & \\
\hline PIV3-F & ACCAGGAAACTATGCTGCAGAACGGC & NP & 234 & 94.45 \\
\hline PIV3-R & GATCCACTGTGTCACCGCTCAATACC & & & \\
\hline PIV4 -F & CAAATGATCCACAGCAAAGATTC & NP & 123 & 92.75 \\
\hline PIV4-R & ATGTGGCCTGTAAGGAAAGCA & & & \\
\hline EV-F & GGCCCCTGAATGCGGCTAATCC & NCR & 151 & 98.76 \\
\hline EV-R & GCGATTGTCACCATAAGCAGTCA & & & \\
\hline RV-F & GGTGTGAAGACTCGCATGTGCT & NCR & 277 & 93.27 \\
\hline RV-R & CCAAAGTAGTCGGTTCCGCTTCTGA & & & \\
\hline RSV-F & GGAACAAGTTGTTGAGGTTTATGAATATGC & $\mathrm{F}$ & 139 & 96.37 \\
\hline RSV-R & TTCTGCTGTCAAGTCTAGTACACTGTAGT & & & \\
\hline HMPV-F & AACCGTGTACTAAGTGATGCACTC & NP & 212 & 90.98 \\
\hline HMPV-R & CATTGTTTGACCGGCCCCATAA & & & \\
\hline
\end{tabular}


In all the sets, cDNA was amplified by a real-time PCR using Power SYBR Green PCR Master Mix Kit (ABI, USA) in OneStep ABI instrument (ABI, USA). Each reaction had a total volume of $25 \mu \mathrm{L}$, including $12.5 \mu \mathrm{L}$ SYBR Green master mix, $200 \mathrm{nmol}$ of each forward and reverse primers, $5 \mu \mathrm{L}$ cDNA plus $7.1 \mu \mathrm{L} \mathrm{ddH}_{2} \mathrm{O}$. The cycling conditions included an initial denaturation step of 10 minutes at $94^{\circ} \mathrm{C}$, followed by 40 cycles of 15 seconds at $95^{\circ} \mathrm{C}$, one minute at $55^{\circ} \mathrm{C}$ and one minute at $60^{\circ} \mathrm{C}$. Fluorescent detection was at the end of each cycle. Melting curve analysis program was used for identification of specific PCR products. After the last cycle, the temperature was increased to $94^{\circ} \mathrm{C}$, then decreased to $75^{\circ} \mathrm{C}$ and slowly increased to $94^{\circ} \mathrm{C}$ at a rate of $0.1^{\circ} \mathrm{C}$ per second, with continuous fluorescence monitoring. Positive and negative controls were added in each set. To prevent contamination, RNA samples and PCR master mixes were prepared under biosafety hoods in different rooms.

\section{Results}

During the September 2012 through September 2013, 3276 throat swab specimens were collected from hospitalized patients of all ages with symptoms of ILI. Initially, all the specimens were tested for influenza viruses by superscript III platinum one-step quantitative real-time PCR assay (Invitrogen, USA), selective for the matrix gene; 2514 samples were negative for influenza viruses. Of which 172 samples were randomly selected for this study. Of 172 specimens, the male:female proportion was 96:76. The mean age was 33.63 years and the median was 31 years. Of 172 samples, in the first set we did not detect any RSV, RV, EV or HMPV. In the second set, there was no PIV1 and PIV2, but 19 (11.04\%) PIV3 and 9 (5.23\%) PIV4 were detected. In the set of coronaviruses NL63, 229E, SARS, OC43, the only detected virus was $1(0.58 \%)$ NL63. This was the first time that human corona virus NL63 was detected in Iran. All the PIV3- and PIV4-positive samples were detected during December to March (Figure 1) and one corona virus NL63 belonged to a 28-day-old newborn in February. Among positive samples, the male:female proportion was 20:9, indicating that males were more affected than females. The mean age was 33.27 years and the median was 32 years. The standard curve and melt curves for positive samples are shown in Figures 2 and 3.

\section{Discussion}

In this study, we described a multiplex SYBR Green real-time PCR assay for detection of 12 respiratory RNA viruses, belonging to three families of viruses: Picornaviridae (RV and EV), Paramyxoviridae (RSV, HMPV, hPIV 1-4) and Coronaviridae (coronaviruses 229E, SARS, NL63, OC43). Enteroviruses and RVs can be detected in $25-30 \%$ of respiratory tract infections. Nearly $80 \%$ of all children have experienced RV infections by the age of two years. Human EV type 68 has been identified in respiratory tract specimens and has been associated with respiratory diseases (14). RSV is the most important cause of severe LRI in infants and young children worldwide. In temperate climates, RSV has been significantly documented as a winter epidemics agent of acute LRI (bronchiolitis and pneumonia) (2). Some studies have reported difficulties in detection of RSV with swabs. RSV lability was suggested as a reason of decreasing the sensitivity of detection (15). HMPV is the cause of $5-7 \%$ of viral respiratory tract infections in hospitalized children (16). HMPV outbreaks usually occur at the same time with the RSV season $(17,18)$. According to the phylogenetic analysis, HMPV is the closest human virus to RSV (19).

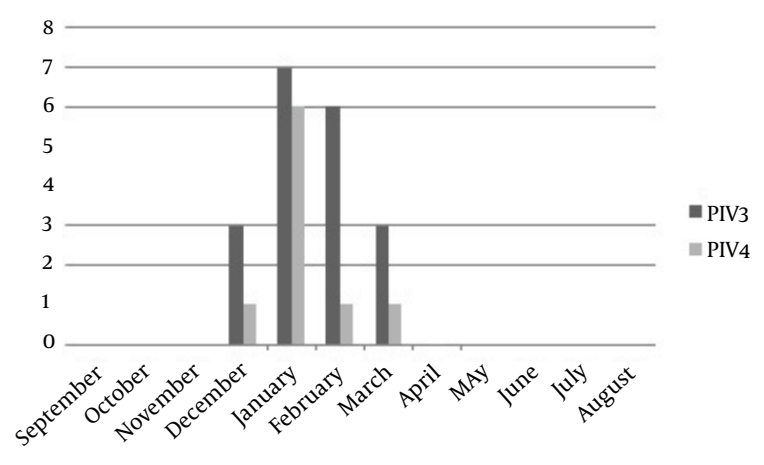

Figure 1. The Prevalence of PIV3 (Black) and PIV4 (Gray) in Different Months of the Study

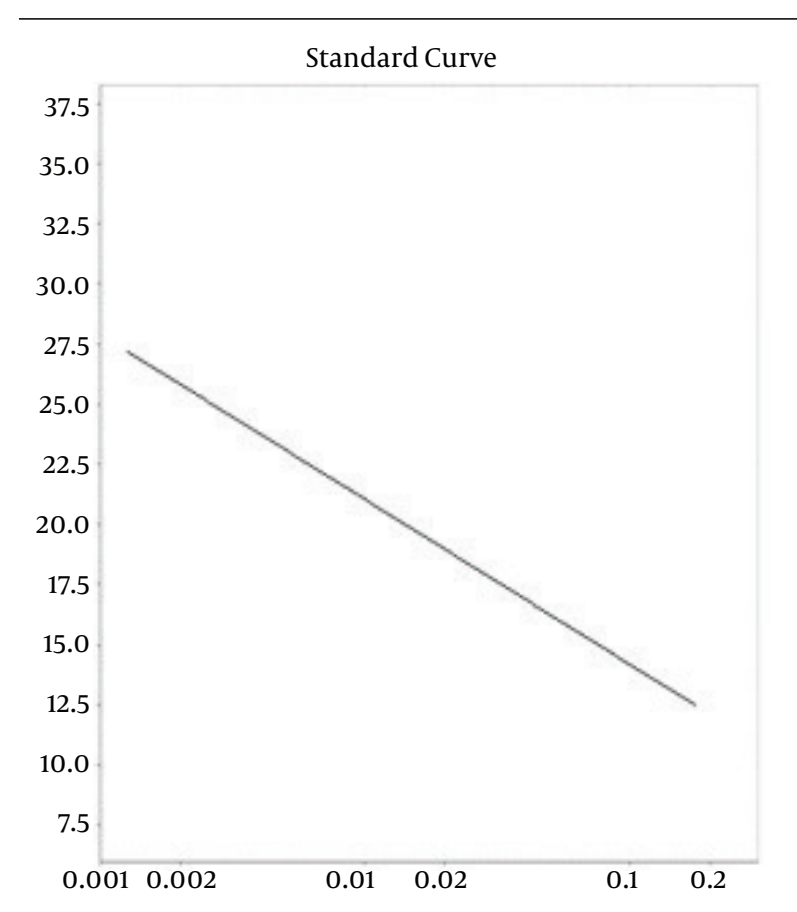

Figure 2. Standard Curve With a Slope of 3.353 and Polymerase Chain Reaction Efficiency of $98.7 \%$ 


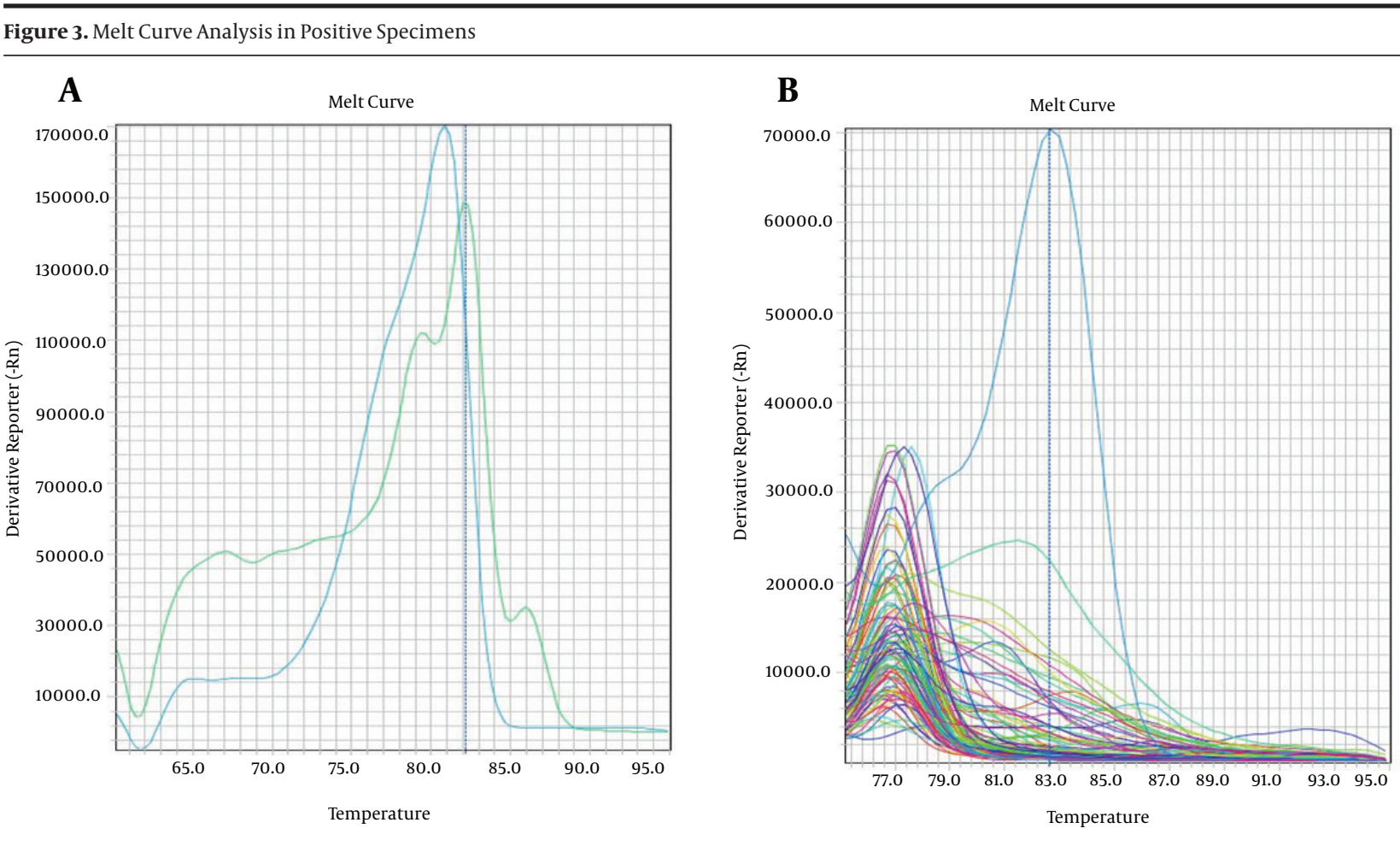

A, PIV3 and PIV4; B, NL-63.

Parainfluenza viruses cause a range of respiratory illness from $30-50 \%$ of URIs including otitis media to $0.3 \%$ of hospitalized children. Croup is one clinical sign of infection with parainfluenza viruses. HPIV1 and HPIV3 are the important causes of upper and lower respiratory tract infections in infants, young children and immunocompromised people (20). Human respiratory coronaviruses infect all age groups. Nearly $10 \%$ of all URI and LRI in children are caused by these viruses (21). Corona viruses are often co-detected with other respiratory viruses, especially RSV (22), but in this study, we did not have co-infections. Respiratory disease can be caused by one of the known respiratory viruses. Nowadays, there are different methods for detection of viruses which may lead to different results. The use of some diagnostic methods such as cell culture might have long delays before the final results. Sensitive and rapid detection of viral infections is essential for reducing the nosocomial transmission and limiting the overuse of antibiotics (15); molecular detection methods have been widely used.

It is notable that singleplex PCR is too arduous, expensive and sample consuming. Multiplex PCR approaches were becoming more and more acceptable for the detection of respiratory viruses, since it is cost- and timeeffective (5). Multiplex conventional PCR has false positive results due to contamination and requires further precautions, more time and two separate machines and facilities (5). Multiplex Taqman real-time PCR is much more expensive than the other methods. In this study, we developed a multiplex SYBR green real-time PCR for detection of 12 RNA respiratory viruses. There were 39 (22.6\%) children less than six years old, in which $1(2.56 \%)$ coronavirus NL63 was detected. Esper et al.(23) identified an incidence of $8.8 \%$ out of 895 pediatric samples positive for coronavirus NL63 annually and a French study found an incidence of $9.3 \%$ out of 300 specimens during five months (24).

One of the reasons for different results in detection of respiratory RNA viruses is using different clinical criteria for selection of patients in different studies. In this study, RV and EVs were not detected, which might have been due to the selection criteria, because we selected the patients hospitalized with respiratory infections, while we knew that RV and EV usually cause mild respiratory infections. We did not detect RSV which is a relatively labile virus and might be lost by freezing and defreezing of the samples. Other limitations of our study were the small sample size and wide age range. The ability of SYBR green real-time PCR in detection of several viruses was assessed and the assay was found easy to use and cost- and time-effective, but for better understanding of sensitivity and specificity, it should be compared with other methods.

\section{Acknowledgements}

The authors thank the entire staff of the National Influenza Center, school of Public Health, Tehran University of Medical Sciences. 


\section{Authors' Contributions}

Study concept and design: Jila Yavarian. Acquisition of data: Azadeh Shadab. Analysis and interpretation of data: Mozhdeh Sultani. Drafting of the manuscript: Owrang Eilami. Critical revision of the manuscript for important intellectual content: Jila Yavarian. Statistical analysis: Mohammadreza Eshragian. Administrative, technical, and material support: Maryam Naseri. Study supervision: Talat Mokhtari Azad.

\section{Funding/Support}

All the phases of this study were supported by Tehran University of Medical Sciences, grant No. 91-02-27-17902.

\section{References}

1. Pyrc K, Stozek K, Wojcik K, Gawron K, Zeglen S, Karolak W, et al. Use of sensitive, broad-spectrum molecular assays and human airway epithelium cultures for detection of respiratory pathogens. PLoS One. 2012;7(3):e32582.

2. Girard MP, Cherian T, Pervikov Y, Kieny MP. A review of vaccine research and development: human acute respiratory infections. Vaccine. 2005;23(50):5708-24.

3. Anzueto A, Niederman MS. Diagnosis and treatment of rhinovirus respiratory infections. Chest. 2003;123(5):1664-72.

4. Brittain-Long R, Nord S, Olofsson S, Westin J, Anderson LM, Lindh M. Multiplex real-time PCR for detection of respiratory tract infections. J Clin Virol. 2008;41(1):53-6.

5. Choudhary ML, Anand SP, Heydari M, Rane G, Potdar VA, Chadha MS, et al. Development of a multiplex one step RT-PCR that detects eighteen respiratory viruses in clinical specimens and comparison with real time RT-PCR. J Virol Methods. 2013;189(1):15-9.

6. Jartti T, Soderlund-Venermo M, Hedman K, Ruuskanen O, Makela MJ. New molecular virus detection methods and their clinical value in lower respiratory tract infections in children. Paediatr Respir Rev. 2013;14(1):38-45.

7. Gunson RN, Collins TC, Carman WF. Real-time RT-PCR detection of 12 respiratory viral infections in four triplex reactions. J Clin Virol. 2005;33(4):341-4.

8. Perez-Ruiz M, Pedrosa-Corral I, Sanbonmatsu-Gamez S, NavarroMari M. Laboratory detection of respiratory viruses by automated techniques. Open Virol J. 2012;6:151-9.

9. Bellau-Pujol S, Vabret A, Legrand L, Dina J, Gouarin S, PetitjeanLecherbonnier J, et al. Development of three multiplex RT-PCR assays for the detection of 12 respiratory RNA viruses. JVirol Methods. 2005;126(1-2):53-63.

10. Mullis K, Faloona F, Scharf S, Saiki R, Horn G, Erlich H. Specific enzymatic amplification of DNA in vitro: the polymerase chain reaction. Cold Spring Harb Symp Quant Biol. 1986;51 Pt 1:263-73.

11. Talbot HK, Falsey AR. The diagnosis of viral respiratory disease in older adults. Clin Infect Dis. 2010;50(5):747-51.

12. Rheem I, Park J, Kim TH, Kim JW. Evaluation of a multiplex realtime PCR assay for the detection of respiratory viruses in clinical specimens. Ann Lab Med. 2012;32(6):399-406.

13. Auburn H, Zuckerman M, Broughton S, Greenough A, Smith M. Detection of nine respiratory RNA viruses using three multiplex RT-PCR assays incorporating a novel RNA internal control transcript. J Virol Methods. 2011;176(1-2):9-13.

14. Meijer A, van der Sanden S, Snijders BE, Jaramillo-Gutierrez G Bont L, van der Ent CK, et al. Emergence and epidemic occurrence of enterovirus 68 respiratory infections in The Netherlands in 2010. Virology. 2012;423(1):49-57.

15. Blaschke AJ, Allison MA, Meyers L, Rogatcheva M, Heyrend C, Mallin $\mathrm{B}$, et al. Non-invasive sample collection for respiratory virus testing by multiplex PCR. J Clin Virol. 2011;52(3):210-4.

16. Kim SR, Ki CS, Lee NY. Rapid detection and identification of 12 respiratory viruses using a dual priming oligonucleotide systembased multiplex PCR assay. J Virol Methods. 2009;156(1-2):111-6.

17. Alto WA. Human metapneumovirus: a newly described respiratory tract pathogen. JAm Board Fam Pract. 2004;17(6):466-9.

18. Prins JM, Wolthers KC. Human metapneumovirus: a new pathogen in children and adults. Neth J Med. 2004;62(6):177-9.

19. Shatizadeh Malekshahi S, Mokhtari Azad T, Shahmahmoodi S, Yavarian J, Rezaei F, Naseri M. First report of respiratory syncytial virus and human metapneumovirus co-infection in a 2-year-old kawasaki patient in iran. Iran J Public Health. 2010;39(4):140-2.

20. Cordey S, Thomas Y, Cherpillod P, van Belle S, Tapparel C, Kaiser L. Simultaneous detection of parainfluenza viruses 1 and 3 by real-time reverse transcription-polymerase chain reaction.J Jirol Methods. 2009;156(1-2):166-8.

21. Dijkman R, Jebbink MF, El Idrissi NB, Pyrc K, Muller MA, Kuijpers TW, et al. Human coronavirus NL63 and 229E seroconversion in children.J Clin Microbiol. 2008;46(7):2368-73.

22. Gaunt ER, Hardie A, Claas EC, Simmonds P, Templeton KE. Epidemiology and clinical presentations of the four human coronaviruses 229E, HKU1, NL63, and OC43 detected over 3 years using a novel multiplex real-time PCR method. J Clin Microbiol. 2010;48(8):2940-7.

23. Esper F, Weibel C, Ferguson D, Landry ML, Kahn JS. Evidence of a novel human coronavirus that is associated with respiratory tract disease in infants and young children.JInfect Dis. 2005;191(4):492-8.

24. Orenstein JM, Banach B, Baker SC. Morphogenesis of Coronavirus HCoV-NL63 in Cell Culture: A Transmission Electron Microscopic Study. Open Infect Dis J. 2008;2:52-8. 